\title{
Matéria
}

ISSN 1517-7076

Revista Matéria, v. 14, n. 4, pp. 1101 - 1113, 2009

http://www.materia.coppe.ufrj.br/sarra/artigos/artigo11102

\section{Prototipagem rápida de Pilhas a Combustível de Óxido Sólido}

\author{
HOTZA, D. \\ Núcleo de Materiais Cerâmicos e Vidros (CERMAT) \\ Universidade Federal de Santa Catarina (UFSC) \\ 88040-900 Florianópolis, SC \\ e-mail:dhotza@pq.cnpq.br
}

\section{RESUMO}

Tecnologias de Prototipagem Rápida (Rapid Prototyping, RP) permitem a fabricação automática de peças com geometria complicada a partir de dados de Projeto Auxiliado por Computador (Computer Aided Design, CAD). A peça tridimensional é construída por consolidação de pó em camadas (processo "aditivo" ou "generativo"). Por isso, estas técnicas estão freqüentemente chamadas de fabricação de forma livre sólida ou fabricação em camadas. Em geral, uma abordagem de 5 etapas do desenvolvimento de produto é comumente aplicada: criação de um modelo de CAD, conversão do modelo de CAD em formato STL, fatiamento do arquivo STL em camadas de seção transversal, fabricação do produto, e finalmente acabamento superficial do produto. Técnicas de RP têm muitos benefícios sobre métodos tradicionais para geração de modelos, ferramentaria e construção de peças de produção de qualidade. Por exemplo, em contraste com processos "subtrativos" (furação, moagem, desbaste) os métodos “aditivos” de RP permitem a fabricação de produtos com estrutura complexa de poros internos que não podem ser fabricados por outros métodos. Técnicas de RP podem diminuir significativamente o tempo de fabricação de pilhas a combustível de óxido sólido (PaCOS) com pequena despesa de operação e reduzido custo de produto quando aplicadas corretamente. Tecnologias como Sinterização Seletiva a Laser (Selective Laser Sintering, SLS), Manufatura de Objetos Laminados (Laminated Object Manufacturing, LOM) e Impressão 3D (3D Printing, 3DP) podem ser usadas para fabricação de protótipos de pilhas a combustível, em particular na configuração planar.

Palavras-chave: prototipagem rápida, pilhas a combustível, SLS, LOM, 3DP.

\section{ABSTRACT}

Rapid prototyping (RP) technologies can automatically manufacture near-net shape parts with complicated geometry from Computer-Aided Design (CAD) data. The three dimensional part is built up by powder consolidation in layers ("additive" or "generative” process). For this reason, these techniques are often referred to as solid freeform fabrication or layered manufacturing. In general, a five-step approach of the product development is commonly applied: creating a CAD model, converting the CAD model into STL format, slicing the STL file into cross-sectional layers, fabrication of the product, and finally surface finishing of the product. RP techniques have many benefits over traditional methods for model generation, tools and even construction of production-quality parts. For instance, in contrast to "subtractive" processes (e.g., drilling, milling, grinding) the "additive"-RP methods allow fabrication of products with complex geometries like undercuts, internal cavities or overhangs that cannot be manufactured by other approaches. Additive RP methods also offer the possibility to generate parts with an orientated internal pore structure. RP techniques can significantly shorten fabrication times of Solid Oxide Fuel Cells (SOFC) with small operational expenditure and reduced product costs when applied properly. Technologies such as Selective Laser Sintering (SLS), Laminated Object Manufacturing (LOM) and 3D Printing (3DP) may be used for the fabrication of fuel cell prototypes particularly for planar configuration.

Keywords: rapid prototyping, fuel cells, SLS, LOM, 3DP. 


\section{INTRODUÇÃO}

A Prototipagem Rápida (Rapid Prototyping, RP), como o nome sugere, foi desenvolvida originalmente para construir protótipos de modo rápido para fins de comunicação e teste [1]. Protótipos melhoram a compreensão, pois a maioria das pessoas, inclusive engenheiros, considera objetos tridimensionais mais fáceis de entender que desenhos bidimensionais. Tais melhorias de comunicação levam a uma economia significativa de custos e tempos. Protótipos também são úteis para avaliar se um projeto tem um desempenho desejado ou precisa de melhoria.

Denominações alternativas têm sido sugeridas para a RP, como Manufatura por Camada (Layer Manufacturing), Fabricação de Forma Livre (Solid Free Form Fabrication), Manufatura de Bancada (Desktop Manufacturing), Manufatura com Acréscimo de Material (Material Incress Manufacturing) [2]. No entanto, o nome original tem prevalecido.

Uma extensão natural da RP é a Manufatura Rápida (Rapid Manufacturing, RM), a produção automatizada de produtos comerciais diretamente a partir de dados de um Projeto Auxiliado por Computador (Computer Aided Design, CAD). Atualmente, poucos produtos acabados são produzidos através de máquinas de RP, mas o número aumentará à medida que cerâmicas, metais e outros materiais se tornem mais amplamente disponíveis []ㅡ.

A RM nunca substituirá completamente outras técnicas industriais, especialmente em lotes grandes de produção, nos quais a produção em massa é mais econômica. Para lotes de produção pequenos, porém, o custo de RM é muito menor, desde que não requeira ferramentaria. A RM também é ideal para peças customizadas, produzidas para suprir as especificações exatas do usuário. Outro uso importante de RM é para produtos que não podem ser feitos através de processos subtrativos (torneamento, fresamento, eletroerosão) ou compressivos (forjamento, estampagem, extrusão), como objetos com características complexas, poros internos, e estruturas em camadas [1- $\underline{1}]$.

A Prototipagem Rápida está começando a mudar o modo pelo qual as empresas projetam e constroem produtos. A introdução de materiais não poliméricos, como cerâmicas e compósitos, representa um desenvolvimento importante. Estes materiais permitem aos usuários de RP produzir peças funcionais. Os protótipos de plástico de hoje funcionam bem para visualização e testes de ajuste, mas eles são freqüentemente muito fracos para teste de funcionabilidade. Materiais mais resistentes produzem protótipos que poderiam ser sujeitos a condições reais de serviço. Além disso, materiais cerâmicos e compósitos ampliam enormemente a gama de produtos que podem ser feitos por fabricação rápida [4].

Por outro lado, os processos convencionais de produção de materiais cerâmicos têm a desvantagem de serem usualmente adequados para produção em massa, mas não para a fabricação rápida e econômica de protótipos ou séries em pequena escala. Considerando que certo número de peças de um produto ou componente é necessário para avaliação de modo a introduzir um material cerâmico para uma determinada aplicação, a capacidade de fabricar tais protótipos em um tempo razoável e por um preço aceitável pode ser um fator decisivo em um mercado competitivo []].

As células a combustível com base em materiais cerâmicos são os dispositivos conhecidos mais eficientes para a conversão eletroquímica de um combustível em energia elétrica [6] . Comparativamente às células a combustível de baixa temperatura, em particular às com base em polímeros, as células ou pilhas a combustível de óxido sólido (PaCOS) operam a temperaturas mais altas, sem a necessidade de catalisadores mais caros, e podem fazer uso de combustíveis alternativos como gás natural e etanol [7].

O presente trabalho apresenta uma breve revisão sobre conceitos e tipos básicos de Prototipagem Rápida, em particular de materiais cerâmicos e compósitos. Além disso, são relatados esforços incipientes no sentido de utilizar técnicas de RP para pilhas a combustível, especialmente para PaCOS.

\section{PROTOTIPAGEM RÁPIDA}

O termo Prototipagem Rápida se refere a uma classe de tecnologias que podem construir modelos físicos automaticamente a partir de dados de CAD. Tais modelos auxiliam visualmente na comunicação de idéias para colegas de trabalho ou clientes. Além disso, protótipos podem ser usados para testes de projetos de modo mais rápido e a um custo menor [1-3] .

Além de protótipos, técnicas de RP podem ser usadas também para fazer ferramentas e mesmo peças de qualidade de produção. Para lotes pequenos de produção e objetos complicados, a prototipagem rápida é freqüentemente o melhor processo industrial disponível. Naturalmente, "rápido" é um termo relativo. A maioria dos protótipos requer de 3 a 72 horas para ser construído, dependendo do tamanho e complexidade do objeto [1]. Isto pode parecer lento, mas é muito mais rápido que semanas ou meses exigidos para fazer um protótipo através de meios tradicionais como usinagem. Essas dramáticas economias de tempo permitem que fabricantes levem produtos para serem comercializados mais rapidamente e a um custo mais baixo. 
Várias técnicas diferentes de RP estão comercialmente disponíveis, cada uma delas com suas especificidades. Prototipagem Rápida é um processo “aditivo”, combinando camadas de papel, cera, plástico ou outro material para criar um objeto sólido. Em contraste, a maioria dos processos de usinagem (cominuição, perfuração, desbaste) são processos “subtrativos” que removem material de um bloco sólido. A natureza aditiva da RP permite criar objetos com características internas complicadas que não podem ser fabricadas através de outros meios.

Naturalmente, a prototipagem rápida não é perfeita. O volume da peça geralmente é limitado a 0,125 $\mathrm{m}^{3}$ ou menos, dependendo da máquina de RP [2]. Protótipos de metal são difíceis de fazer, entretanto isto deve mudar no futuro próximo. Para peças de metal, lotes grandes de produção, ou objetos simples, técnicas industriais convencionais são normalmente mais econômicas. A não ser por estas limitações, a prototipagem rápida é uma tecnologia notável que está revolucionando o processo industrial.

\subsection{Conceitos básicos}

Todas as técnicas de RP empregam o mesmo processo básico de 5 passos, conforme Figura 1 [8]]:

- Criação de um modelo de CAD do projeto (Figura 1a)

- $\quad$ Conversão do modelo de CAD para um formato STL (Figura 1b)

- $\quad$ Fatiamento do arquivo STL em camadas finas de seção transversal (Figura 1c-e)

- Construção do modelo de camada sobre camada (Figura 1f)

- Limpeza e acabamento do modelo.

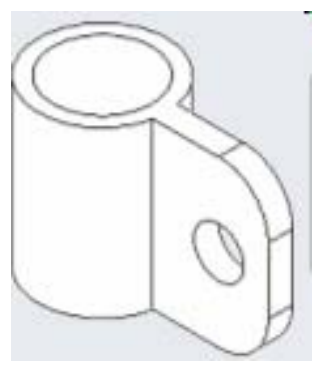

(a)

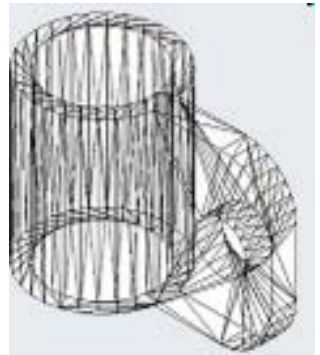

(b)

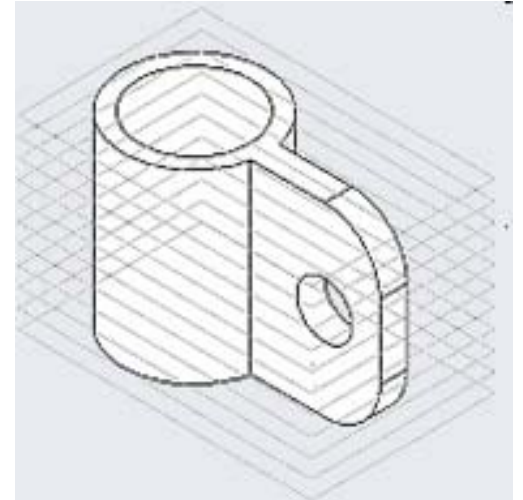

(c)

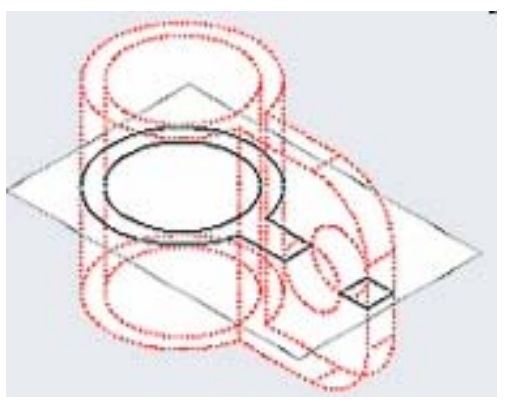

(d)

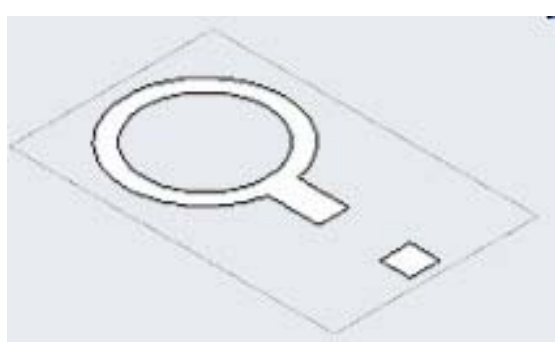

(e)

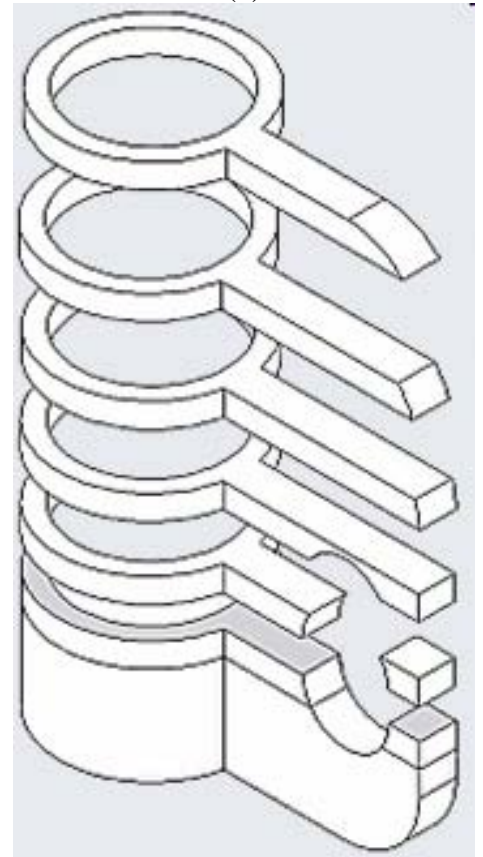

(f)

Figura 1: Representação das principais etapas do processo de manufatura por camada []]. 


\subsubsection{Criação de um modelo de CAD}

Primeiramente, o objeto a ser construído é modelado usando um software que fatia o modelo de CAD em um certo número de camadas finas que são construídas então umas sobre as outras. Modelos sólidos (Figura 1a) tendem a representar objetos 3-D mais precisamente que modelos de armação de arame e dão resultados melhores. O projetista pode usar um arquivo de CAD pré-existente ou pode criar um arquivo exclusivamente para propósitos de prototipagem. Este processo é idêntico para todas as técnicas de construção de RP.

\subsubsection{Conversão para formato STL}

Os vários softwares de CAD usam algoritmos diferentes para representar objetos sólidos. Para estabelecer consistência, o formato STL (de estereolitografia, a primeira técnica de RP) foi adotado como o padrão da indústria de prototipagem rápida. Então, o segundo passo é converter o arquivo de CAD para formato STL. Este formato representa uma superfície tridimensional como uma montagem de triângulos planares (Figura 1b). O arquivo contém as coordenadas dos vértices e a direção da normal externa de cada triângulo. Como o arquivo STL usa elementos planares, estes não podem representar curvas de modo exato. Aumentando o número de triângulos melhora a aproximação, mas às custas de um tamanho de arquivo maior. Arquivos grandes e complicados requerem mais tempo para pré-processamento e construção, assim o projetista tem que equilibrar precisão com facilidade para produzir um arquivo STL útil. Considerando que o formato STL é universal, esse processo é idêntico para todas as construções técnicas de RP.

\subsubsection{Fatiamento do arquivo}

No terceiro passo, um programa de pré-processamento prepara o arquivo de STL para ser construído. Vários programas estão disponíveis, e a maioria permite ao usuário ajustar o tamanho, localização e orientação do modelo. A orientação de construção é importante por várias razões. Primeiramente, as propriedades dos protótipos variam de acordo com a direção da coordenada. Por exemplo, os protótipos são normalmente mais fracos e menos precisos na direção z (vertical) do que no plano $\mathrm{x}$-y. Além disso, a orientação da peça determina parcialmente o período de tempo exigido para se construir o modelo. Colocando-se a dimensão mais curta na direção z, reduz-se o número de camadas, encurtando assim o tempo de construção. O software de pré-processamento fatia o modelo STL em várias camadas de $0,01 \mathrm{~mm}$ a $0,7 \mathrm{~mm}$ de espessura, dependendo da técnica de construção (Figura 1c-e). O programa também pode gerar uma estrutura auxiliar para apoiar o modelo durante a construção. Apoios são úteis para características delicadas como partes pendentes, cavidades internas, e seções de parede fina. Cada fabricante de máquina de RP fornece um software de pré-processamento específico.

\subsubsection{Construção do modelo de camadas}

O quarto passo é a construção real da peça (Figura 1f). Usando uma dentre várias técnicas (descritas na próxima seção), as máquinas de RP constroem uma camada de cada vez a partir de um polímero, papel, pó metálico ou outro material de partida. A maioria das máquinas é bastante autônoma, precisando de pequena intervenção humana.

\subsubsection{Limpeza e acabamento}

O passo final é o pós-processamento. A etapa envolve a remoção do protótipo da máquina e a separação de algum apoio. Certos materiais fotossensíveis precisam ser curados completamente antes do uso. Protótipos também podem requerer limpeza secundária e tratamento de superfície. Lixamento, marcação e/ou pintura do modelo podem melhorar sua aparência e durabilidade.

\subsection{Principais processos}

Existem mais de 20 sistemas de RP no mercado que, apesar de usarem diferentes tecnologias de adição de material, estão baseadas no mesmo principio de manufatura por camadas planas [9]. Os processos de RP atualmente mais importantes, considerando equipamentos instalados e processos promissores, estão descritos brevemente a seguir.

\subsubsection{Estereolitografia}

Patenteada em 1986, a estereolitografia (StereoLithography, SL), começou a revolução da prototipagem rápida. A técnica constrói modelos tridimensionais de polímeros fotossensíveis líquidos que solidificam quando expostos à luz ultravioleta [2]. Como mostrado na Figura 2, o modelo é construído em uma plataforma, situada sob a superfície em um recipiente de resina epóxi ou acrílica líquida. Um laser de baixa potência traça a primeira camada, solidificando a seção transversal do modelo deixando líquidas as 
áreas em excesso. Em seguida, um elevador abaixa de passo em passo a plataforma para dentro do polímero líquido. Um varredor recobre a camada solidificada com líquido, e o laser traça a segunda camada sobre a primeira. Este processo é repetido até o protótipo estar completo. Depois, a parte sólida é afastada do recipiente e limpo de líquido em excesso. Apoios são rompidos para fora e o modelo é colocado então em um forno ultravioleta (UV) para completar a cura.

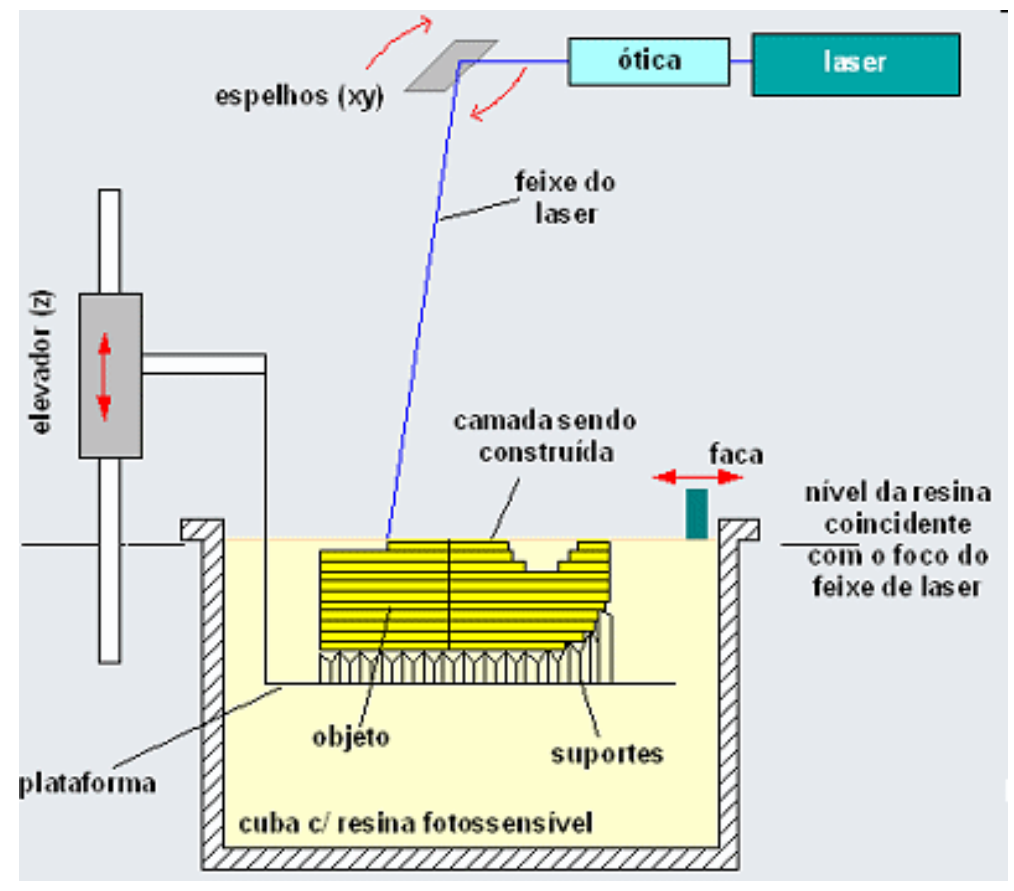

Figura 2: Diagrama esquemático da SL []].

Os materiais fotocuráveis disponíveis atualmente são resinas acrílicas e epóxi. Algumas pesquisas apontam para a possibilidade de fabricação de peças reforçadas com fibras de carbono [2]. Adicionalmente, pós cerâmicos podem ser adicionados a resinas curável em UV, de modo a formar uma peça a verde, posteriormente tratada termicamente para eliminação da resina e sinterização da peça [10 $\underline{10}]$.

\subsubsection{Modelagem por fusão e deposição}

Na Modelagem por Fusão e Deposição (Fused Deposition Modelling, FDM), filamentos de termoplásticos são extrudados a partir do aquecimento de uma matriz que se move no plano x-y (Figura 3). Como um confeiteiro decorando um bolo, o cabeçote controlado de extrusão deposita quantidades pequenas de material sobre a plataforma de construção para formar a primeira camada. A plataforma é mantida a uma temperatura mais baixa, de forma que os termoplásticos endureçam rapidamente. Depois que a plataforma abaixa, o cabeçote de extrusão deposita uma segunda camada sobre a primeira. São construídos apoios no caminho, firmados à peça com um segundo material mais frágil ou com uma junção picotada.

Os seguintes materiais estão atualmente disponíveis para a construção de protótipos nesse processo: cera, poliéster, acrilonitrila butadieno estireno (ABS), policarbonato (PC) e polifenilsulfona (PPSF) [2] ]. Uma versão para deposição de materiais cerâmicos (também chamada de Fused Deposition of Ceramics, FDC) deve incluir a eliminação de ligantes e a sinterização [13, $\underline{14]}$. 


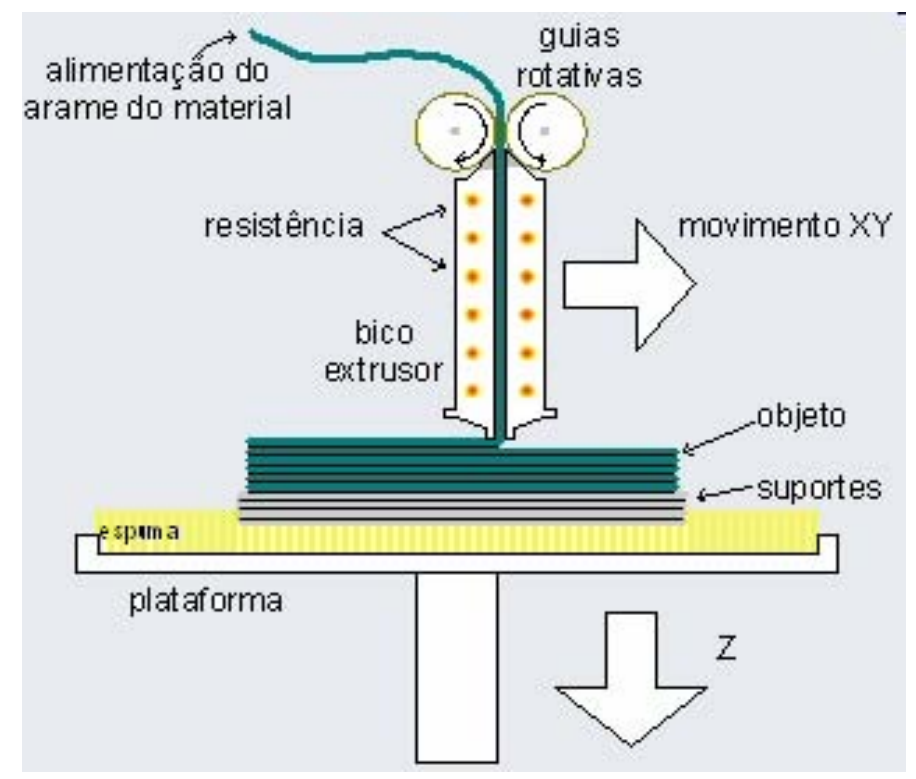

Figura 3: Diagrama esquemático da FDM [8].

\subsubsection{Manufatura de objetos laminados}

Na Manufatura de Objetos Laminados (Laminated Object Manufacturing, LOM), camadas de material em forma de fitas cobertas com adesivo são ligadas para formar um protótipo. O material original consiste em papel laminado com cola ativada pelo calor e enrolada em carretéis. Como mostrado na Figura 4, um mecanismo alimentador/coletor avança a folha sobre a plataforma de construção onde uma base foi construída de papel e fita de dupla face. Então, um rolo aquecido aplica pressão para unir o papel à base. Um laser focalizado corta o contorno da primeira camada no papel e destaca a área em excesso (espaço negativo no protótipo), para facilitar a remoção durante o pós-processamento. Durante a construção, o material em excesso fornece um apoio para partes pendentes e seções de parede fina. Depois que a primeira camada é cortada, a plataforma se afasta do caminho e o material fresco é alimentado. A plataforma avança ligeiramente para abaixo da altura prévia, o rolo une a segunda camada à primeira, e o laser corta a segunda camada. Este processo é repetido tantas vezes quando necessário para construir a peça que terá uma textura de madeira. Como os modelos são feitos de papel, eles devem ser selados e acabados com tinta ou verniz para prevenir dano por umidade.

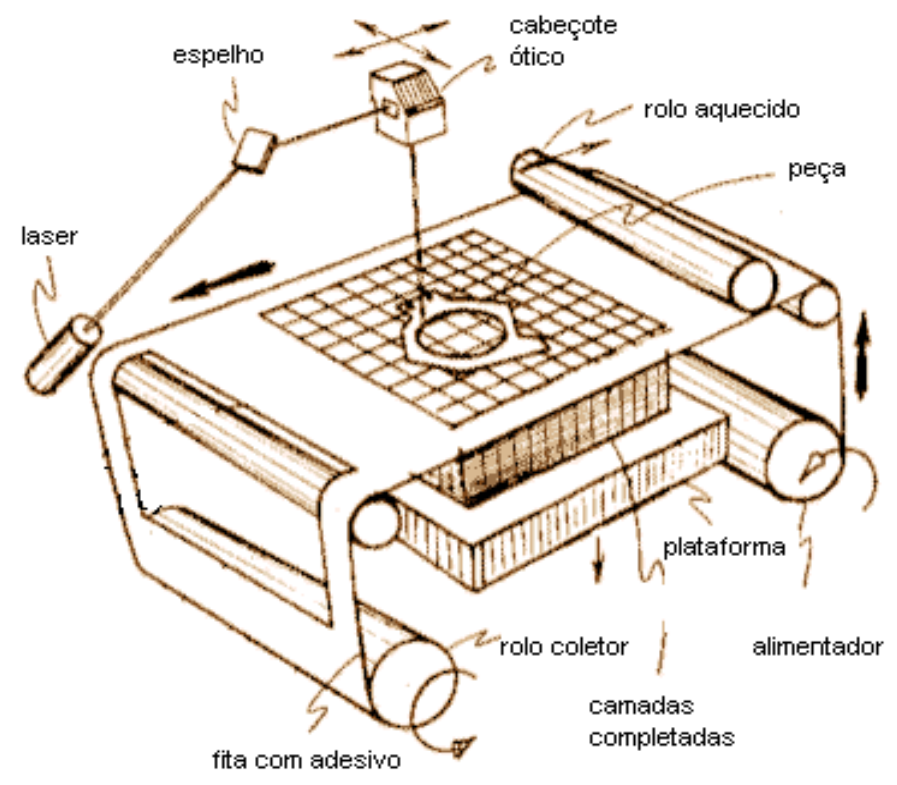

Figura 4: Diagrama esquemático da LOM []]. 
Foram desenvolvidos vários materiais novos de fitas, inclusive plásticos, papéis hidrofóbicos, e fitas de pós vítreos, cerâmicos e metálicos [2]. As fitas de pós cerâmicos produzem uma peça a verde que deve ser sinterizada aumentar a resistência [15-17].

\subsubsection{Sinterização seletiva a laser}

A sinterização seletiva a laser (Selective Laser Sintering, SLS) foi patenteada em 1989. A técnica, mostrada na Figura 5, usa um feixe de laser para ligar seletivamente materiais sob a forma de pó, como nylon, elastômeros e metais em um objeto sólido. Peças são construídas sobre uma plataforma pouco abaixo da superfície em um recipiente do pó fundível pelo calor. Um laser traça o padrão da primeira camada, fazendo com que esta sinterize. A plataforma é abaixada para a altura da próxima camada e o pó é reaplicado. O processo continua até a peça estar completa. Pó em excesso em cada camada ajuda apoiar a peça durante a construção.

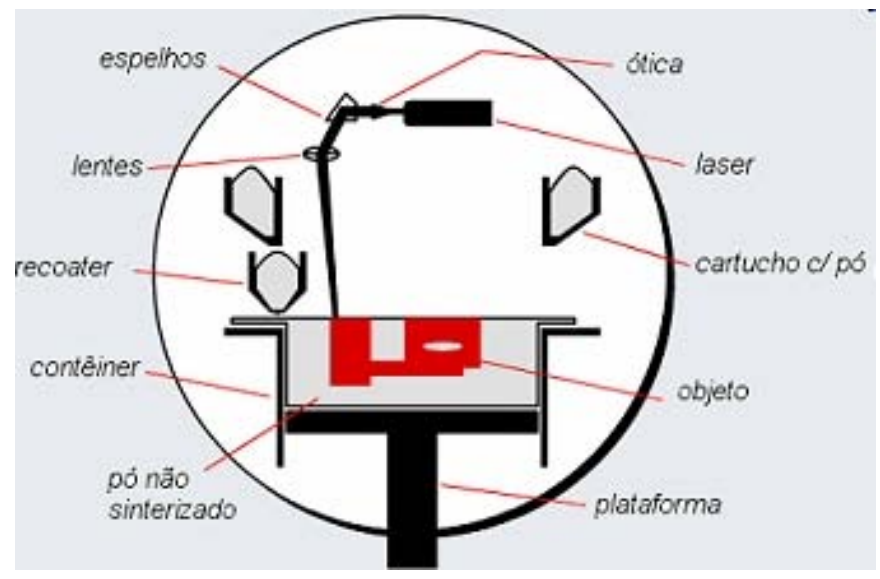

Figura 5: Diagrama esquemático da SLS [8].

Os materiais disponíveis para a tecnologia SLS são náilon, poliamida, elastômeros, além de cerâmicas e metais usando polímeros como aditivos [2]. Esta técnica ainda está em desenvolvimento para materiais cerâmicos, devido a dificuldades advindas da sinterização [18]. No entanto, estruturas podem ser densificadas completamente por sinterização com fase líquida [19,20].

\subsubsection{Impressão tridimensional}

A Impressão 3D (3D Printing, 3DP), como mostrado na Figura 6, são construídas peças em uma plataforma situada em um recipiente cheio de material em pó. Um cabeçote de jato-de-tinta seletivamente "imprime” um fluido ligante para fundir o pó nas áreas desejadas. O pó não ligado permanece para apoiar a peça. A plataforma é abaixada, mais pó acrescentado e nivelado, e o processo, repetido. Quando termina, a peça a verde é então afastada do pó não ligado, e o pó não ligado em excesso é eliminado. Peças acabadas podem ser infiltradas com cera, cola, ou outro selante para melhorar a durabilidade e o acabamento superficial. A espessura de camada típica está na ordem de 0,1 mm. Este processo é muito rápido, e produz peças com uma superfície ligeiramente granulada.

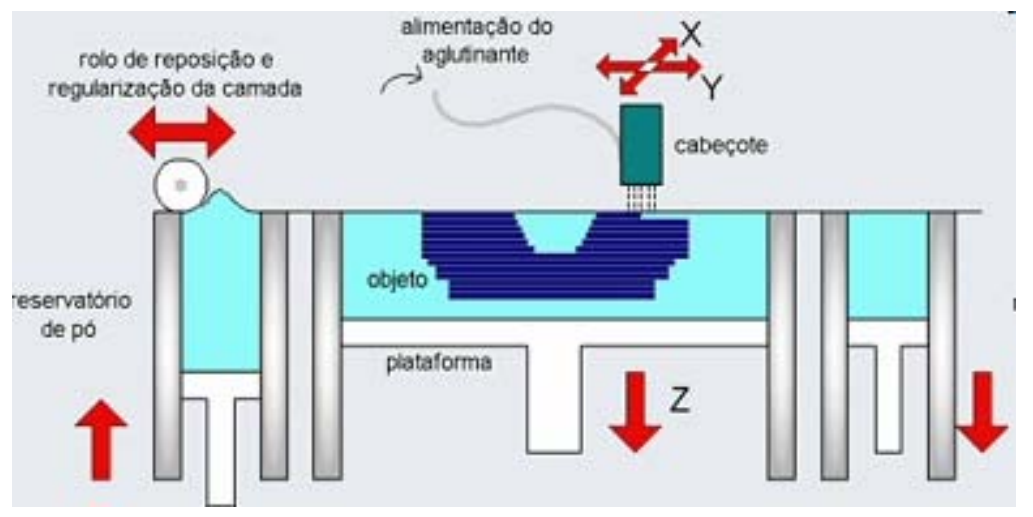

Figura 6: Diagrama esquemático da 3DP []] 
Em princípio, não há limitação quanto aos materiais que podem ser utilizados neste processo, sendo comum o uso de amido, gesso, polímeros, pós cerâmicos e metálicos [2]. No caso de materiais cerâmicos, esse podem estar presentes tanto no pó quanto no material aglutinante [21-26].

\section{PILHAS A COMBUSTÍVEL DE ÓXIDO SÓLIDO}

O processamento e a caracterização de PaCOS tem sido alvo de intensa pesquisa tanto na academia quanto na indústria. Na maior parte dos casos, os produtos se encontram em fase de desenvolvimento, iniciação de fabricação e testes de protótipos. Nessas etapas, ressalta-se a importância das técnicas de prototipagem virtual e física.

A seguir são apresentadas as configurações mais comuns de PaCOS, as técnicas de RP relatadas na literatura para a fabricação de pilhas a combustível, bem como um sumário de perspectivas de uso de RP para elaboração de protótipos de PaCOS.

\subsection{Configurações e processos de fabricação}

As configurações de PaCOS mais usadas são a planar e a tubular. Essas opções definem os materiais e os processos a serem empregados na fabricação das pilhas. Neste trabalho, a discussão será limitada à configuração planar, visto que, como o nome sugere, neste tipo de PaCOS as células unitárias estão dispostas de forma plana conectadas em série. Cada plano corresponde a um componente (eletrólito, eletrodos) com espessura, composição e densidade característica (Figura 7). Pode-se facilmente associar a configuração planar de uma PaCOS com a característica básica de todas as técnicas de RP, que é a adição de material em camadas planas sucessivas.

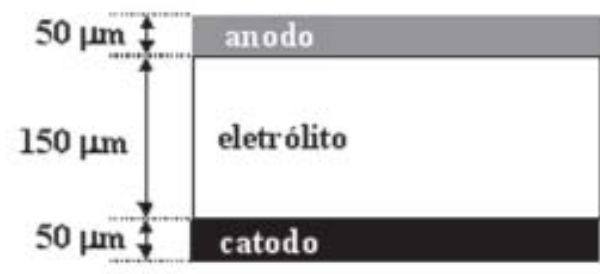

(a)

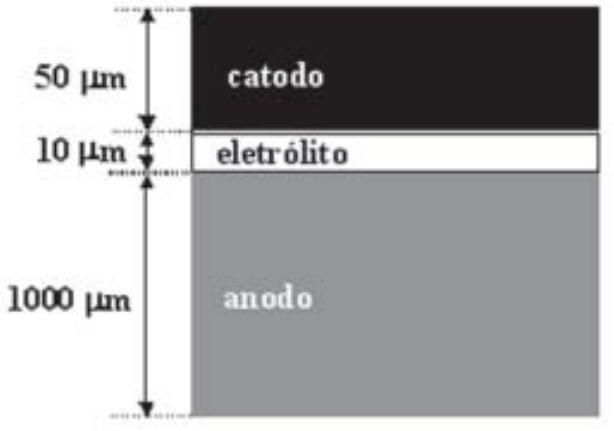

(b)

Figura 6: Diagrama esquemático de uma célula unitária de PaCOS planar: (a) suportada no eletrólito, (b) suportada no anodo [6]

A fabricação dos componentes das PaCOS planares pode ser por processos particulados ou por deposição. Em todos os casos o eletrólito, em geral a base de zircônia estabilizada com ítria (ZEI), deve ser denso, com espessuras variáveis: $\sim 150 \mu \mathrm{m}$ no caso de células suportadas no eletrólito (Figura 6a) ou $\sim 10 \mu \mathrm{m}$ para células suportadas no anodo []]. Já os anodos (geralmente ZEI com adição de níquel) e os catodos (usualmente a base de manganita de lantânio dopada com estrôncio) devem ser porosos para permitir a passagem de gases combustíveis e de produtos de combustão, respectivamente [27].

Os processos particulados incluem colagem de fita (tape casting) ou calandragem de fita (tape calendering). Já os processos de deposição incluem recobrimento por imersão (dip coating), recobrimento sob rotação (spin coating), pirólise por jateamento (spray pirolysis), eletroforese, colagem a vácuo (vacuum casting), entre outros [6] .

Por outro lado, o fluxo e a distribuição de gases numa PaCOS planar podem ser arranjados em fluxo cruzado (cross flow), contracorrente (counter-flow) ou paralelo (co-flow). A seleção do tipo de configuração de fluxo influencia de maneira importante a distribuição de temperatura e de corrente nas pilhas [్] ]. Um esquema de PaCOS planar, por exemplo, chamada de monobloco, se baseia em um eletrólito corrugado sobre o qual são depositadas as camadas de eletrodos (Figura 7). A própria célula possui canais para o fluxo de gases, simplificando o formato dos interconectores (neste caso a base de cromita de lantânio) e dos selantes (geralmente a base de vidros ou vitrocerâmicos). 


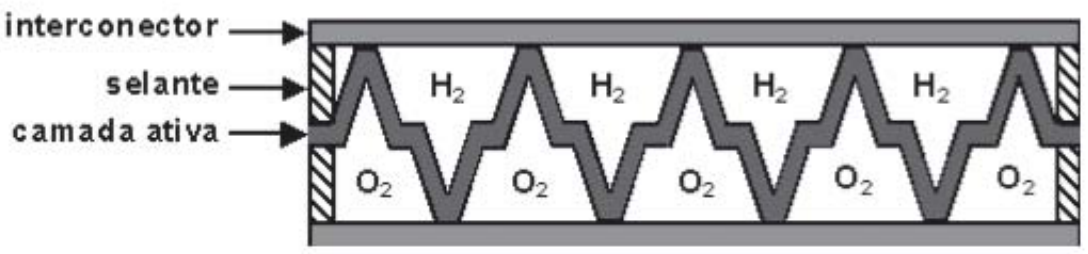

Figura 7: Exemplo de configuração monobloco de PaCOS planar [28].

\subsection{Fabricação de pilhas a combustível por RP}

ZHENG [29] relata numa patente americana a fabricação de uma PaCOS monolítica por SLS, consistindo de várias camadas triplas (eletrólito, eletrodos), além de padrões para difusão de gases também construídos em camadas (Figura 8). O inventor afirma que se trata de um processo de baixo custo, de alta velocidade de fabricação.

COULON e GIRAUD [30] patentearam um método de fabricação de PaCOS que envolve a solidificação parcial de uma camada de pó por SLS para formar uma seção de uma pilha. Uma camada sucessiva de pó se deposita sobre a camada inicial e o processo se repete até que toda a configuração da pilha seja construída (Figura 8b). O método, segundo os inventores, elimina uma etapa adicional de montagem mecânica. A pilha pode ser formada por várias unidades de células.

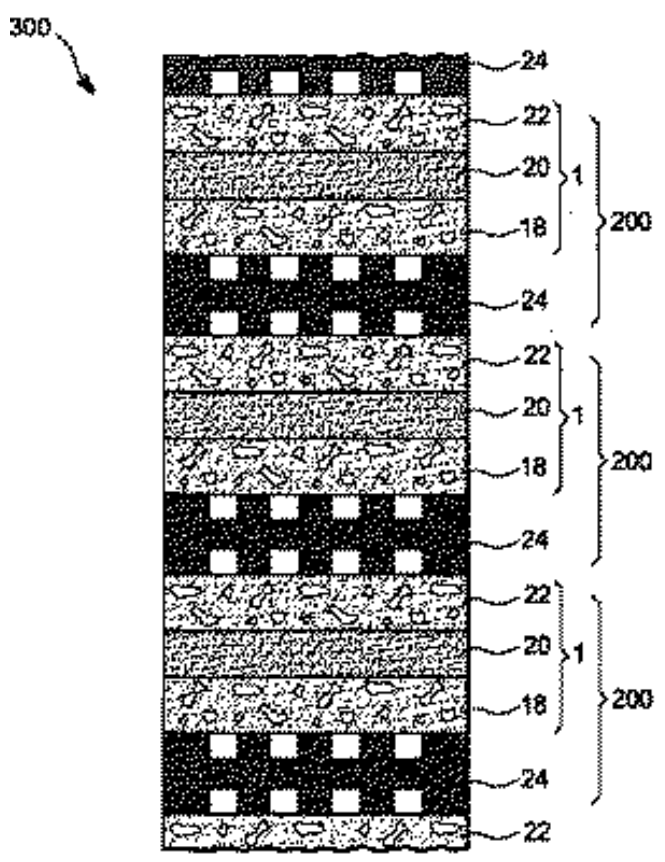

(a)

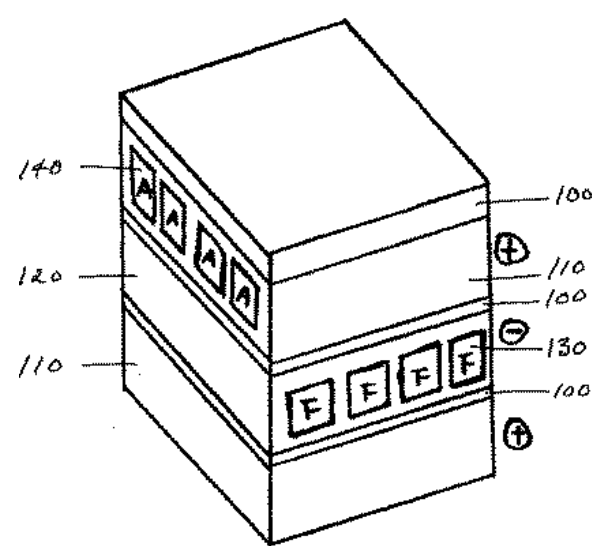

(b)

Figura 8: Configurações de PaCOS fabricadas por SLS: (a) pilha [29], (b) célula unitária [30].

CHYOU et al. [31] focaram seu estudo no design térmico de unidades de PaCOS, empregando materiais isolantes para redução de perdas por calor. Uma metodologia computacional foi empregada para caracterizar uma PaCOS planar típica (Figura 9a), utilizando um modelo bidimensional (Figura 9b) de elementos finitos para análise termomecânica em processos iterativos e bidimensional (Figura 9c) para adaptação a processos de RP. 


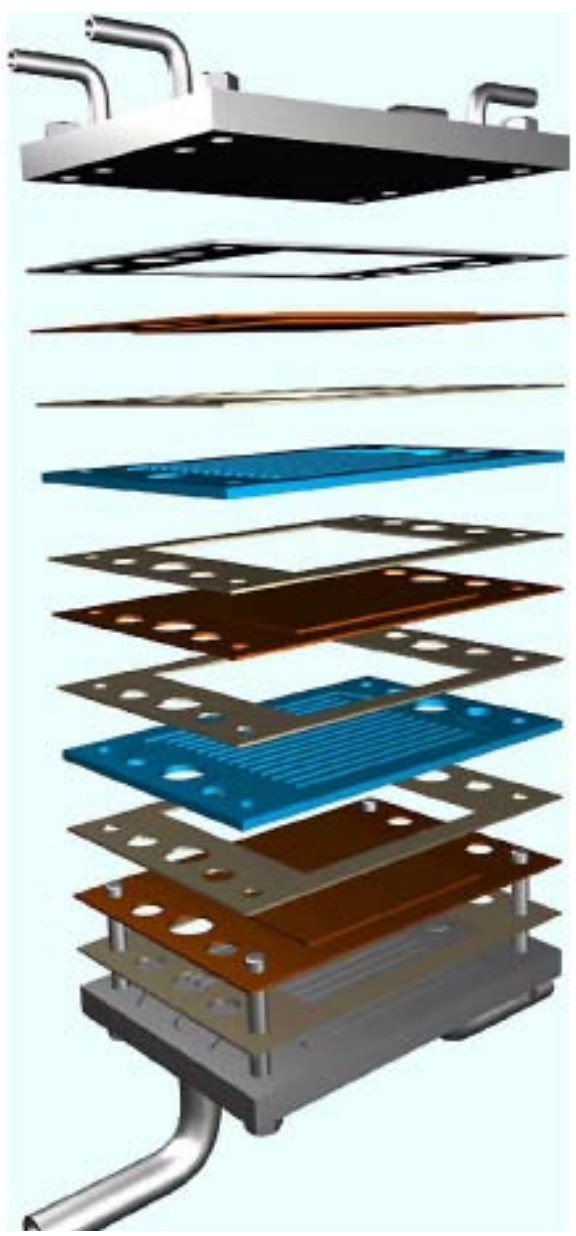

(a)

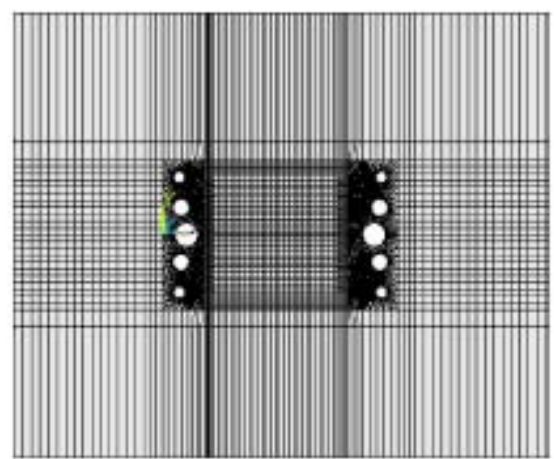

(b)

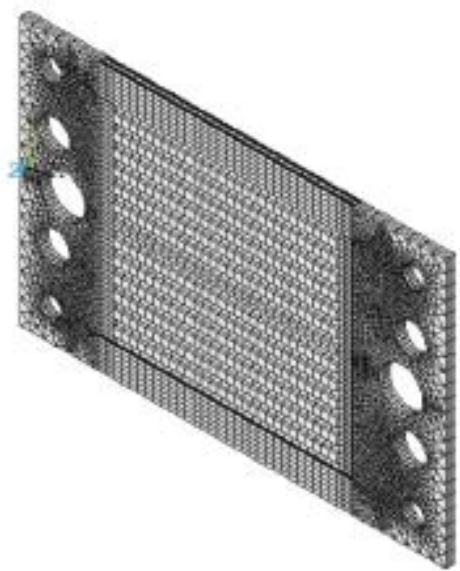

(c)

Figura 9: Modelos computacionais de PaCOS planar: (a) montagem da pilha, (b) e malhas de elementos finitos em (b) 2D e (c) 3D [31].

CHEN et al. [32] afirmaram em artigo recente serem os primeiros tanto na área acadêmica quanto industrial a fabricar uma pilha a combustível de configuração planar (neste caso, uma pilha de membrana polimérica) utilizando uma técnica de prototipagem rápida. Os autores argumentaram que o tempo de manufatura empregado foi de aproximadamente $1 \mathrm{~h}$, enquanto que em técnicas convencionais o tempo estimado de fabricação seria de 12 a 36 h. No entanto, detalhes do método de RP empregado não foram revelados.

\subsection{Sumário das técnicas de RP aplicáveis para fabricação de Pacos}

A Tabela 1 apresenta um quadro comparativo das tecnologias de RP disponíveis comercialmente. Há vários outros processos não descritos aqui por serem recentes ou pouco representativos no mercado [2] .

A escolha do sistema a ser utilizado é fortemente influenciada pela função que o protótipo terá que desempenhar, desde puramente visuais até produtos finais. Essas áreas de atuação, prototipagem e produção final, parecem ser o espaço que já vem sendo e será ocupado pelas tecnologias de RP [ㄹ] 
Tabela 1: Resumo comparativo de tecnologias típicas de RP com potencial aplicação em manufatura de PaCOS [2].

\begin{tabular}{|c|c|c|c|c|c|}
\hline $\begin{array}{c}\text { Característica/ } \\
\text { Processo }\end{array}$ & SL & FDM & LOM & SLS & 3DP \\
\hline $\begin{array}{l}\text { Custo inicial de } \\
\text { aquisição }\end{array}$ & Alto & Médio & Médio & Alto & Baixo \\
\hline $\begin{array}{l}\text { Custo do } \\
\text { material }\end{array}$ & Alto & Alto & Baixo & Médio & Médio \\
\hline $\begin{array}{l}\text { Custo do } \\
\text { protótipo }\end{array}$ & Alto & Médio & Baixo & Alto & Baixo \\
\hline Precisão & Alta & Média & Baixa & Média & Baixa \\
\hline $\begin{array}{l}\text { Tamanho } \\
\text { máximo de } \\
\text { peças (mm) }\end{array}$ & $\begin{array}{c}508 \times 508 \times \\
584\end{array}$ & $\begin{array}{c}600 \times 500 \times \\
600\end{array}$ & $\begin{array}{c}813 \times 559 \times \\
508\end{array}$ & $\begin{array}{c}381 \times 330 \times \\
457\end{array}$ & $\begin{array}{c}508 \times 609 \times \\
406\end{array}$ \\
\hline
\end{tabular}

No caso específico de PaCOS planares, as técnicas SLS, LOM e 3DP parecem apresentar vantagens expressivas. Na SLS os processos de conformação e sinterização são simultâneos, proporcionando uma economia de tempo e energia dispendidos no processo $[\underline{29}, \underline{30}]$, que compensaria o custo de aquisição inicial do equipamento e dos materiais empregados. Na LOM pode-se fazer uso de técnicas convencionais já consagradas (como tape casting) para obtenção de estruturas laminares (fitas) com composições e microestruturas otimizadas para cada componente da pilha [17]. Além disso, para LOM e 3DP, apesar da necessidade de uma etapa de tratamento térmico, o custo total do processo tende a ser comparativamente menor devido a equipamentos e/ou materiais menos dispendiosos.

\section{CONCLUSÕES}

A prototipagem rápida se caracteriza por ser um processo de manufatura de baixo custo e de alta flexibilidade para a produção de protótipos funcionais e produtos customizados. Seu princípio de funcionamento se baseia na superposição de camadas que vão formando um desenho tridimensional de variada complexidade, através de diversas técnicas.

Pilhas a combustível de oxido sólido, em particular aquelas de configuração planar, podem ser descritas como conjuntos de componentes (eletrodos, eletrólito, interconectores, selantes) dispostos em camadas, com características peculiares a cada função exercida.

Os processos convencionais de fabricação de PaCOS demandam tempos e custos altos, especialmente na etapa de desenvolvimento e otimização de produtos. As técnicas de sinterização seletiva a laser (SLS), Manufatura de Objetos Laminados (LOM) e Impressão Tridimensional (3DP) se apresentam como alternativas promissoras para fabricação de protótipos de pilhas a combustível.

Na SLS, apesar do alto custo inicial do equipamento, pode-se conformar e sinterizar os componentes simultaneamente. Duas patentes recentes registram o uso dessa técnica para fabricação de PaCOS. Na LOM, podem ser usadas fitas produzidas por tape casting para obtenção de laminados. Já a 3DP apresenta os menores custos de aquisição do equipamento e de fabricação do protótipo. 


\section{AGRADECIMENTOS}

Ao CNPq, pelo suporte financeiro, e à Rede PaCOS, pela oportunidade de participar do $5^{\circ}$ Seminário da Rede.

\section{BIBLIOGRAFIA}

[1] PALM, W., Rapid prototypin processes, http://www.me.psu.edu/lamancusa/rapidpro/primer/chapter2.htm Acessado em março de 2009.

[2] VOLPATO, N. (Editor), Prototipagem rápida: tecnologias e aplicações, São Paulo, Blücher, 2007.

[3] KOCHAN, D., CHUA, C.K., "State-of-the-art and future trends in advanced rapid prototyping and manufacturing”, International Journal of Information Technology, v. 1, n. 2, pp. 173-184, 1995.

[4] LINO, F.J., NETO, R.J.L., PAIVA, R., et al., "Rapid prototyping and rapid tooling applied in product development of ceramic components”, Materials Science Forum, v. 455-456, pp. 835-838, 2004.

[5] JANSSEN, R., SCHEPPOKAT, S., CLAUSSEN, N., "Tailor-made ceramic-based components: Advantages by reactive processing and advanced shaping techniques", Journal of the European Ceramic Society, v. 28, pp. 1369-1379, 2008.

[6] FLORIO, D.Z., VARELA, J.A., FONSECA, F.C., MUCCILLO, E.N.S., MUCCILLO, R., "Direcionamentos da tecnologia industrial de células a combustível de óxido sólido", Química Nova, v. 30, n. 5, pp. 1339-1346, 2007.

[7] SILVA, M.A., BOAVENTURA, J.S., ALENCAR, M.G., CERQUEIRA, C.P., "Desenvolvimento de protótipo de células a combustível do tipo óxido sólido com reforma direta”, Revista Matéria, v. 12, n. 1, pp. 99-110, 2007.

[8] CIMJECT, http://www.cimject.ufsc.br. Acessado em março de 2009.

[9] KAI, C.C., FAI, L.K., SING, L.C., Rapid prototyping: principles and applications, 2nd ed., Manufacturing World, 2003.

[10] GRIFFITH, M.L., HALLORAN, J.W., "Freeform fabrication of ceramics via stereolithography", Journal of the American Ceramic Society, v. 79, n. 10, pp. 2601-2608, 1996.

[11] GRECO, A., LICCIULLI, A., MAFFEZZOLI, A., “Stereolithography of ceramic suspensions”, Journal of Materials Science, v. 36, n. 1, pp. 99-105, 2001.

[12] CHARTIER, T., CHAPUT, C., ABOULIATIM, Y., DELAGE, C., "Rapid prototyping: fabrication of three-dimension complex parts by stereolithography”, Ceramic Forum International, v. 83, n. 5, pp. E102-E108, 2006.

[13] AGARWALA, M. K., BANDYOPADHYAY, A., VAN WEEREN, R., SAFARI, A., DANFOTH, S.C., LANGRANA, N.A. et al., "FDC: rapid fabrication of structural components", American Ceramic Society Bulletin, v. 75, n. 11, pp. 60-65, 1996.

[14] ALLAHVERDI, M., DANFORTH, S.C., JAFARI, M., SAFARI, A., "Processing of advanced electroceramic components by fused deposition technique”, Journal of the European Ceramic Society, v. 21, n. 10/11, pp. 1485-1490, 2001.

[15] KLOSTERMAN, D.R., CHARTOFF, R., OSBORNE, N., GRAVES, G., "Laminated object manufacturing, a new process for the direct manufacture of monolithic ceramics and continuous fiber CMCs”, Ceramic Engineering and Science Proceedings, v. 18, n. 4, pp. 113-120, 1997.

[16] WEISENSEL, L., TRAVITZKY, N., SIEBER, H., GREIL, P., "Laminated object manufacturing (LOM) of SiSiC composites”, Advanced Engineering Materials, v. 6, n. 11, pp. 899-903, 2004. 
[17] GOMES, C.M., OLIVEIRA, A.P.N., HOTZA, D., TRAVITZKY, N., GREIL, P., "LZSA glass-ceramic laminates: fabrication and mechanical properties”, Journal of Materials Processing Technology, v. 206, pp. 194-201, 2008.

[18] LEE, I., "Densification of porous Al2O3-Al4B2O9 ceramic composites fabricated by SLS process', Journal of Materials Science Letters, v. 18, n. 19, pp. 1557-1561, 1999.

[19] KLOCKE, F., MCCLUNG, A., ADER, C., 'Direct laser sintering of borosilicate glass”, In: Proceedings of the 15th Annual SFF Symposium 2004 on Solid Freeform Fabrication, pp. 214-219, 2004.

[20] GUNSTER, J., HEINRICH, J.G., SCHWERTFEGER, G., "Laser sintering of ultra pure SiO2 crucibles. International Journal of Applied Ceramic Technology, v. 3, pp. 68-74, 2006.

[21] TENG, W.D., EDIRISINGHE, M.J., "Development of continuous direct ink-jet printing of ceramics”, British Ceramic Transactions, v. 97, pp. 169-173, 1998.

[22] SONG, J.H., EDIRISINGHE, M.J., EVANS, J.R.G., "Formulation and multilayer jet printing of ceramic inks”, Journal of the American Ceramic Society, v. 82, n. 12, pp. 3374 -3380, 1999.

[23] DERBY, B., REIS, N., “Inkjet printing of highly loaded particulate suspensions”, MRS Bulletin, v. 28, n. 11, pp. 815-818, 2003.

[24] WANG, H.R., CIMA, M.J., KERNAN, B.D., SACHS, E.M., “Alumina doped silica gradient-index (GRIN) lenses by slurry-based-three-dimensional printing”, Journal of Non-Crystalline Solids, v. 349, n. 1-3, pp. 360-367, 2004.

[25] SEITZ, H., RIEDER,W., IRSEN, S., LEUKERS, B., TILLE, C., “Three-dimensional printing of porous ceramic scaffolds for bone tissue engineering”, Journal of Biomedical Materials Research, v. 74B, n. 2, pp. 782-788, 2005.

[26] WANG, T., DERBY, B., “Ink-jet printing and sintering of PZT”, Journal of the American Ceramic Society, v. 88, n. 8, pp. 2053-2058, 2005.

[27] AMADO, R.S., MALTA, L.F.B., GARRIDO, F.M.S., MEDEIROS, M.E., "Pilhas a combustível de óxido sólido: materiais, componentes e configurações”, Química Nova, v. 30, n. 1, pp. 189-197, 2007.

[28] NAKANISHI, A., HATTORI, M., SAKAKI, Y., MIYAMOTO, H., AIKI, H., TAKENOBU, K., NISHIURA, M., Proceedings of the Fifth European SOFC Forum, Lucerne, Switzerland, 2002.

[29] ZHENG, Y., "Monolithic fuel cell comprises several triplex anode-electrolyte-cathode layers, and substrate interconnect gas diffusion flow field layer constructs having fuel and oxidizer passages", Patent Numbers US2003235738-A1, US6838203-B2, 2004.

[30] COULON, N., GIRAUD, S., "Fuel cell e.g. solid oxide fuel cell, assembly fabricating method for e.g. auxiliary power unit, involves partially solidifying previously disposed and successive powder layers by laser sintering”, Patent Numbers: FR2880199-A1, WO2006070150-A2, EP1829148-A2, US2008008826-A1, CN101088190-A, JP2008525953-W, 2006.

[31] CHYOU, Y.P.; CHUNG, T.D., CHEN, J.S., SHIE, R.F., “Integrated thermal engineering analyses with heat transfer at periphery of planar solid oxide fuel cell”, Journal of Power Sources, v. 139, pp. 126140, 2005.

[32] CHEN, C.Y., LAI, W.H., WENG, B.J., CHUANG, H.J., HSIEH, C.Y., KUNG, C.C., "Planar array stack design aided by rapid prototyping in development of air-breathing PEMFC”, Journal of Power Sources, v. 179, pp. 147-154, 2008. 